\title{
The Sex Ratio of Orange-flanked Bush-robins (Aves: Passeriformes: Muscicapidae) from a Winter Population in Central China
}

\author{
Jianqiang $\mathrm{Li}^{\mathrm{a}, \mathrm{b}}$, Zhengwang Zhang ${ }^{\mathrm{b}}$, Yong Wang ${ }^{\mathrm{b}, \mathrm{c}}$, Chang $\mathrm{Gao}^{\mathrm{b}}$, Jiliang $\mathrm{Xu}^{\mathrm{a}}$, Bo $\mathrm{Xi}^{\mathrm{d}}$, \\ Jiagui Zhu ${ }^{d}$ and Zhiyong $\mathrm{Du}^{\mathrm{d}}$

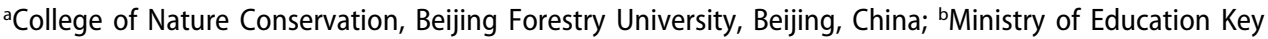 \\ Laboratory for Biodiversity Sciences and Ecological Engineering, College of Life Sciences, Beijing Normal \\ University, Beijing, China; 'Department of Biological and Environmental Sciences, College of Agriculture, \\ Life, and Natural Sciences, Alabama A\&M University, Normal, AL, USA; ${ }^{d}$ Adiministrition Bureau of Dongzhai \\ National Nature Reserve, Luoshan, Henan, China
}

\begin{abstract}
The sex ratio of a population is an important demographic parameter, but compared with breeding populations, the sex ratios of avian winter populations have received relatively little attention. The orange-flanked bush-robin (Tarsiger cyanurus) is a migratory species whose plumage is sexually dimorphic with delayed plumage maturation wherein first-year males show female-like plumage. We investigated the sex ratio of an orange-flanked bush-robin population wintering in Dongzhai National Nature Reserve located in central China. The results show that most (> 85\%) orange-flanked bush-robins of this population have female-like plumage, implying that the population sex ratio might be female-biased. However, genetic analysis revealed that most (c. 70\%) individuals with female-like plumage were males, resulting in a significantly male-biased population sex ratio. Among the individuals with female-like plumage, the males were found to have significantly longer wings and tails than females, but the accuracy of a discriminant analysis employing the two morphological traits to sex them was low. The results suggest that a genetic method is a more appropriate way to sex those orange-flanked bushrobins with female-like plumage and more importantly, one needs to be cautious when using the morphology of individuals to infer the sex ratio of a population for species like orange-flanked bush-robins.
\end{abstract}

\section{ARTICLE HISTORY}

Received 20 March 2015

Accepted 5 October 2015

Online 1 December 2015

\section{KEYWORDS}

orange-flanked bush-robin; sex; sex ratio; Tarsiger cyanurus; winter population

\section{Introduction}

The sex ratio of a population is an important demographic parameter that is related to a variety of life history and behavioural characteristics, such as growth and extinction (Le Galliard et al. 2005; Lenz et al. 2007), mating system and breeding behaviour (Liker et al. 2014; Székely et al. 2014). Although many studies have investigated the sex ratio of adult bird populations (Donald 2007), most focused on the sex ratio of breeding populations, with winter populations receiving relatively less attention (but see Ketterson and Nolan 1979; Marra 2000; Stouffer et al. 2003; Catry et al. 2005 for 
examples). However, studies have revealed that due to factors such as sex-specific habitat requirements (Zharikov and Skilleter 2002) and dominance-mediated habitat segregation (Marra 2000), the two sexes of a species may differ in their spatial distribution in winter, leading to unequal sex ratios in certain habitats or areas. Knowledge of the sex ratio of a species' winter population may therefore help to understand its life history and behavioural strategies, and may be important for the conservation of specific habitats for one sex or another of endangered species (Gray et al. 2009).

For some bird species, it is relatively easier to investigate their population sex ratios if the two sexes differ in plumage. However, delayed plumage maturation, a phenomenon in which males maintain female-like plumage until after the first potential breeding season (Studd and Robertson 1985; Hawkins et al. 2012), often exists in sexually dimorphic species such as lazuli bunting (Passerina amoena) (Muehter et al. 1997) and red-backed fairy-wren (Malurus melanocephalus) (Karubian et al. 2008) and may make sex idenfication difficult in the field.

The orange-flanked bush-robin (Tarsiger cyanurus), also known as the red-flanked bluetail (e.g. Gill and Donsker 2015), is a small passerine bird distributed in Eurasia. The species breeds in northern Asia and northeastern Europe and winters in southeastern and southern Asia (Collar 2005). The plumage of adult male orange-flanked bush-robins is deep blue above, with brighter blue on the crown, shoulder, rump and tail base. Females, in contrast, are olive-brown above, with blue only on the rump and tail (Collar 2005). Orange-flanked bush-robins have delayed plumage maturation (Morimoto et al. 2006). The appearance of first-year males is therefore similar to that of females, which makes it difficult to distinguish them in the field.

Previous studies on orange-flanked bush-robins have investigated aspects like their ecology and behaviour (e.g. Gao and Li 1983; Morimoto et al. 2006; Wang et al. 2006), but the sex ratio of any of their populations has never been reported despite the species' broad distribution across Eurasia. During our years of fieldwork in a natural reserve in central China, we found that most orange-flanked bush-robins wintering in our study area were overwhelmingly female-like in plumage, with individuals of adult-male plumage only occasionally seen (J. Li, pers. obs.). Although it is likely that some individuals with female plumage were actually young males, the extraordinarily high proportion of female-like individuals led us to speculate that the sex ratio of this wintering population was femalebiased. To test this idea and investigate the exact sex ratio, we captured the robins over three winters and determined their sexes using genetic methods.

\section{Methods}

\section{Study site and field methods}

The population was located in the Dongzhai National Nature Reserve $\left(31.95^{\circ} \mathrm{N}, 114.25^{\circ} \mathrm{E}\right.$; altitude, $100-840 \mathrm{~m}$ ), which is in the southern part of Henan Province in central China and encompasses part of the Dabieshan Mountains. The area is at the transitional region of the subtropical and temperate zones and so is characterized by rich avian diversity (for more information of the study area, see Li et al. 2009).

In the winters (December, January and February) of 2008-2009, 2010-2011 and 20112012, 14-40 mist-nets were set along trails on the bottoms of three valleys at Baiyun 
protection station in the reserve. The habitats in the three valleys were similar and were characterized by shrub species such as young oriental oak (Quercus variabilis), bamboo (Pleioblastus spp.) and glaucous allspice (Lindera glauca), and tree species such as masson pine (Pinus massoniana), dyetree (Platycarya strobilacea) and oaks (Quercus spp.). The mist-netting lasted 23, 20 and 10 days, respectively, during the three winters. Except for the winter of 2008-2009, most birds were recorded as either having femalelike plumage or having adult-male plumage and from most individuals we took six morphological measurements including bill length, bill-head length and tarsus length using digital callipers $( \pm 0.01 \mathrm{~mm})$, and wing length, tail length and total body length using a ruler $( \pm 0.5 \mathrm{~mm}$ ). The body mass of the birds was determined using a digital balance $( \pm 0.01 \mathrm{~g})$.

\section{Sex determination using genetic methods}

We took blood samples from the robins through venepuncture of the brachial vein and extracted genomic DNA using a TIANamp Genomic DNA kit (TianGen Biotech, Co., Ltd., Beijing, China). The sexes of the birds were determined using the genetic primer pair sex1'/sex2 (see Wang et al. 2010 for details of the method).

\section{Statistics}

We used binomial tests to detect deviations in the population sex ratio from parity. Comparisons of morphological differences in most of the measurements between females and female-like first-year males were conducted using independent $t$-tests, with an exception for bill-head length and tarsus length, the data for which did not follow normal distribution and were analysed with Mann-Whitney U-tests. Because of the limitation of sample size, the morphological measurements of $\geq 2$-year-old males were not statistically compared with those of females and female-like first-year males (determined with genetic methods). We also did not compare the morphological size difference between first-winter females and $\geq 2$-year-old females, as we were unable to discriminate them based on their plumage. In an attempt to establish a way to distinguish the female-like first-year males from the females, we conducted a discriminant function analysis (using stepwise approach) with the morphological characters that had significant differences between them. Accuracy of the discriminant function was evaluated using leave-one-out cross-validation (Zavalaga et al. 2009).

Only individuals captured in the winter of 2010-2011 were involved in the above analyses with regard to morphological traits. This is because most individuals during that period were measured by a single person (J.L.; individuals not measured by J.L. were not included in the analysis). All the statistical analyses were conducted in SPSS 19.0 (SPSS Inc., Chicago, IL, USA) and tests were considered significant when $p<0.05$.

\section{Results}

We captured 18, 84 and 35 orange-flanked bush-robins in the winters of 2008-2009, 2010-2011 and 2011-2012, respectively. We only recorded the plumage types of the robins in the latter two winters. Among the individuals for which we have records of 
Table 1. Comparison of morphological measurements of orange-flanked bush-robins in the Dongzhai National Nature Reserve of central China.

\begin{tabular}{|c|c|c|c|c|c|c|c|c|c|}
\hline & \multicolumn{3}{|c|}{ Females } & \multicolumn{3}{|c|}{ Female-like males } & \multicolumn{3}{|c|}{ Adult males } \\
\hline & $n$ & Mean & SD & $n$ & Mean & SD & $n$ & Mean & SD \\
\hline Body mass (g) & 16 & 13.54 & 0.90 & 41 & 13.64 & 1.03 & 3 & 13.93 & 0.99 \\
\hline Bill-head length (mm) & 14 & 31.38 & 0.92 & 36 & 31.27 & 3.05 & 3 & 31.37 & 0.48 \\
\hline Bill length $(\mathrm{mm})$ & 14 & 9.09 & 0.76 & 36 & 9.00 & 0.50 & 3 & 9.43 & 0.12 \\
\hline Tarsus length (mm) & 14 & 22.28 & 0.64 & 36 & 21.61 & 3.41 & 3 & 21.50 & 1.20 \\
\hline Wing length (mm) & 14 & 74.4 & 3.4 & 36 & 77.7 & 1.6 & 3 & 77.5 & 2.78 \\
\hline Body length (mm) & 14 & 131.2 & 3.3 & 36 & 133.8 & 4.8 & 3 & 133.2 & 3.3 \\
\hline Tail length (mm) & 14 & 55.4 & 2.0 & 36 & 57.2 & 2.3 & 3 & 57.5 & 2.8 \\
\hline
\end{tabular}

their plumage type, $92.8 \%(77 / 83)$ in $2010-2011$ and $86.2 \%(25 / 29)$ in $2011-2012$ were female-like.

Using genetic methods, 18, 80 and 30 individuals captured in the three respective winters were successfully sexed. The population sex ratios (proportion of males) were $77.8 \%$ in $2008-2009,77.5 \%$ in $2010-2011$ and $70.0 \%$ in $2011-2012$, all significantly biased toward males (binomial tests, $p=0.031,<0.001$, and $p=0.043$ for the three respective winters). For the individuals with female-like plumage in the winters of 20102011 and $2011-2012,72.7 \%$ (56/77) and 68.0\% (17/25), respectively, were identified as males.

The measurements of the females, female-like first-year males and old males captured in the winter of 2010-2011 are shown in Table 1. Among the seven measurements, female-like males were significantly larger than females in wing length (Table 1 ; independent $t$-test, $t_{15}=3.4, p=0.004$ ) and tail length (Table 1 ; independent $t$-test, $t_{48}=4.6$, $p=0.015$ ), and were similar in other measurements (Table 1 ; independent $t$-tests or Mann-Whitney $U$-tests, all $p>0.5$ ). The stepwise discriminant analysis involved both wing and tail lengths for distinguishing females and female-like males in the discriminant function: $D=0.388 \times$ wing length $+0.210 \times$ tail length -41.711 . An individual was classified as a female when $D<-0.361$ (cut-off value) and a male when $D>-0.361$. Cross-validation showed that the accuracy of the function was $64.3 \%$ for females and $77.8 \%$ for female-like males.

\section{Discussion}

The mist-netting suggested that most (> 85\%) orange-flanked bush-robins wintering in the Dongzhai National Reserve had female-like plumage, which was consistent with our field observations. However, contrary to our speculation that the population sex ratio was female-biased, our genetic analysis revealed that individuals with female-like plumage were mostly males (c. 70\%). As a result, the sex ratio of this winter population was significantly biased toward males (i.e. $70 \%$ to nearly $80 \%$ of the individuals were males in the three winters). This result suggests the need for caution when using plumage to infer the sex and sex ratio of orange-flanked bush-robins as well as other species with delayed plumage maturation.

In the comparison of morphological difference between females and female-like young males, we found that the wing and tail lengths of the female-like males were longer than those of females. However, the attempt for sexing individuals with female-like plumage 
using these two measurements produced a discriminant function with low accuracy. Therefore we suggest that a genetic method should be used for sexing these individuals and the wing and tail lengths can only be used to infer their sexes when other approaches are not available.

It is interesting that few male orange-flanked bush-robins $\geq 2$ years old were observed in this population, which, we think, may be due to the following two nonexclusive reasons. The first is that because of their bright blue plumage, adult males probably suffer higher mortality during the migration from the breeding ground to the wintering ground. This is possible, as in a study of the stopover ecology of migrating orange-flanked bush-robins at a site in northeast China, which is close to their breeding ground, the reported numbers of female-plumage and male-plumage individuals in autumn were nearly equal (390 versus 367) (Wang et al. 2006).

The second possibility for the rarity of old males is that males of different ages may differ in their wintering areas, as what has been documented in other species. For example, the immature males of American goldfinches (Spinus tristis) winter farther north than adult males (Prescott and Middleton 1990) and older and younger male American redstarts (Setophaga ruticilla) winter in different habitats, with dominant older males more likely to occupy the preferred mangrove habitats (Marra 2000). If the orange-flanked bush-robins of different ages also have different wintering areas, it may result in the rarity of adult males in the population we studied as well. Currently, we have some evidence to support the idea that adult males winter south of our study area, because every spring we have noticed an increase in the number of individuals with adult-male plumage during their migration period ( $\mathrm{J}$. Li, personal observation); however, the possibility of some young males moulting into adult plumage at this time cannot be excluded.

In addition to the rarity of older males, another notable point of the results is the male-biased population sex ratio. Biased sex ratio could be the result of sampling bias caused by a sex-specific capture probability (Amrhein et al. 2012). Although we currently cannot exclude this possibility, other reasons may also account for the pattern. For example, the winter population sex ratio may reflect the sex ratio of their breeding populations in the north. Also, like the wintering distribution in relation to age, female and male orange-flanked bush-robins may differ in their wintering grounds, a phenomenon frequently observed in migratory birds (Ketterson and Nolan 1979; Stouffer et al. 2003; Catry et al. 2005). Besides, because of differences in plumage coloration (e.g. hooded warbler, Wilsonia citrina; Lynch et al. 1985; Stutchbury 1994), dominance status (e.g. American redstarts; Marra 2000) and arrival date (American kestrels, Falco sparverius; Smallwood 1988), females and males may winter in the same grounds but may occupy different habitats. Clarification of these possibilities requires investigations of their sex ratios in their breeding grounds, through their migration and wintering ranges, and in different habitats.

\section{Acknowledgements}

We thank Yang Qiu, Myung-bok Lee, Jiao Wang, Yingying Liu and many other students for help with the collection of the data, and the Dongzhai National Nature Reserve for their permission and 
assistance with this study. We are also grateful to Andrew Cantrell and two anonymous reviewers for their constructive comments and suggestions, which greatly improved the manuscript.

\section{Disclosure statement}

No potential conflict of interest was reported by the authors.

\section{Funding}

Financial support was provided by the Forestry Commonweal Programme (No. 201404422) and the National Natural Science Foundation of China (No. 31101644; No. 31472011).

\section{References}

Amrhein V, Scaar B, Baumann M, Minéry N, Binnert J-P, Korner-Nievergelt F. 2012. Estimating adult sex ratios from bird mist netting data. Method Ecol Evol. 3:713-720.

Catry P, Lecoq M, Araújo A, Conway G, Felgueiras M, King JMB, Rumsey S, Salima H, Tenreiro P. 2005. Differential migration of chiffchaffs Phylloscopus collybita and P. ibericus in Europe and Africa. J Avian Biol. 36:184-190.

Collar NJ. 2005. Family Turdidae (thrushes). In: del Hoyo J, Elliott A, Christie DA, editors. Handbook of birds of the world, volume 10: cuckoo-shrikes to thrushes. Barcelona: Lynx Edicions; p. 514-807.

Donald PF. 2007. Adult sex ratios in wild bird populations. Ibis. 149:671-692.

Gao W, Li F. 1983. Observations on the breeding ecology and habits of Red-flanked Bush Robin (Tarsiger cyanurus). Chin J Zool. 18:7-10. Chinese.

Gill F, Donsker D. 2015. IOC World Bird List (v5.1) [Internet]. [cited 2015 Feb 18]. Available from: http://www.worldbirdnames.org/

Gray TN, Chamnan H, Collar NJ, Dolman PM. 2009. Sex-specific habitat use by a lekking bustard: conserv implications for the critically endangered bengal florican (Houbaropsis Bengalensis) in an intensifying agroecosystem. Auk. 126:112-122.

Hawkins GL, Hill GE, Mercadante A. 2012. Delayed plumage maturation and delayed reproductive investment in birds. Biol Rev. 87:257-274.

Karubian J, Sillett TS, Webster MS. 2008. The effects of delayed plumage maturation on aggression and survival in male red-backed fairy-wrens. Behav Ecol. 19:508-516.

Ketterson ED, Nolan Jr V. 1979. Seasonal, annual, and geographic variation in sex ratio of wintering populations of Dark-eyed Juncos (Junco hyemalis). Auk. 96:532-536.

Le Galliard J-F, Fitze PS, Ferrière R, Clobert J. 2005. Sex ratio bias, male aggression, and population collapse in lizards. Proc Natl Acad Sci USA. 102:18231-18236.

Lenz T, Jacob A, Wedekind C. 2007. Manipulating sex ratio to increase population growth: the example of the Lesser Kestrel. Anim Conserv. 10:236-244.

Li J, Lin S, Wang Y, Zhang Z. 2009. Nest-dismantling behavior of the hair-crested drongo in central China: an adaptive behavior for increasing fitness? Condor. 111:197-201.

Liker A, Freckleton RP, Székely T. 2014. Divorce and infidelity are associated with skewed adult sex ratios in birds. Curr Biol. 24:880-884.

Lynch JF, Morton ES, Van der Voort ME. 1985. Habitat segregation between the sexes of wintering Hooded Warblers (Wilsonia citrina). Auk. 102:714-721.

Marra PP. 2000. The role of behavioral dominance in structuring patterns of habitat occupancy in a migrant bird during the nonbreeding season. Behav Ecol. 11:299-308.

Morimoto G, Yamaguchi N, Ueda K. 2006. Plumage color as a status signal in male-male interaction in the red-flanked bushrobin, Tarsiger cyanurus. J Ethol. 24:261-266.

Muehter VR, Greene E, Ratcliffe L. 1997. Delayed plumage maturation in Lazuli buntings: tests of the female mimicry and status signalling hypotheses. Behav Ecol Sociobiol. 41:281-290. 
Prescott DR, Middleton AL. 1990. Age and sex differences in winter distribution of American Goldfinches in eastern North America. Ornis Scand. 21:99-104.

Smallwood JA. 1988. A mechanism of sexual segregation by habitat in American Kestrels (Falco sparverius) wintering in south-central Florida. Auk. 105:36-46.

Stouffer PC, Dwyer GM, Moore F. 2003. Sex-biased winter distribution and timing of migration of Hermit Thrushes (Catharus guttatus) in eastern North America. Auk. 120:836-847.

Studd MV, Robertson RJ. 1985. Life span, competition, and delayed plumage maturation in male passerines: the breeding threshold hypothesis. Am Nat. 126:101-115.

Stutchbury BJ. 1994. Competition for winter territories in a Neotropical migrant: the role of age, sex and color. Auk. 111:63-69.

Székely T, Weissing F, Komdeur J. 2014. Adult sex ratio variation: implications for breeding system evolution. J Evol Biol. 27:1500-1512.

Wang N, Li J, Liu Y, Zhang Z. 2010. Improvement on molecular sex identification primers for Passeriform bird species. Chin Birds. 1:65-69.

Wang Y, Chang J, Moore FR, Su L, Cui L, Yang X. 2006. Stopover ecology of Red-flanked Bush Robin (Tarsiger cyanurus) at Maoershan, Northeast China. Acta Ecol Sin. 26:638-646.

Zavalaga CB, Taylor SA, Dell'omo G, Anderson DJ, Friesen VL. 2009. Male/female classification of the Peruvian booby. Wilson J Ornithol. 121:739-744.

Zharikov Y, Skilleter GA. 2002. Sex-specific intertidal habitat use in subtropically wintering Bartailed Godwits. Can J Zool. 80:1918-1929. 